\title{
IDENTIFIKASI SEBARAN MINERAL SULFIDA (PIRIT) MENGGUNAKAN METODE GEOMAGNET DI DAERAH LIBURENG KABUPATEN BONE
}

\author{
Muh. Zulfitrah ${ }^{1}$, Lantu ${ }^{1 *}$, Syamsuddin ${ }^{1}$ \\ ${ }^{I}$ Program Studi Geofisika, FMIPA Universitas Hasanuddin, Makassar, Indonesia \\ *Penulis koresponden. Alamat email: geolantu@gmail.com
}

\begin{abstract}
Abstrak
Penelitian ini dilakukan dengan metode geomagnet di daerah Libureng kabupaten Bone, Sulawesi Selatan. Ada 65 titik pengukuran dengan luas $120 \mathrm{~m}$ untuk mengidentifikasi sebaran mineral sulfida. Panjang lintasan $100 \mathrm{~m}$ dengan spasi $20 \mathrm{~m}$ menggunakan satu alat magnetometer. Koreksi data dengan filter upward continuation serta metode foward modeling menggunakan perangkat lunak Mag2dc. Dari hasil analisis data diperoleh nilai anomali berkisar antara -1700 sampai $8000 \mathrm{nT}$. Interpretasi menujukkan Batuan beku andesit (1.6801 x $\left.10^{-3} \mathrm{SI}\right)$ yang mengintrusi batuan sedimen batugamping $\left(0.3554 \times 10^{-3} \mathrm{SI}\right)$. Mineral sulfida disseminated dan berasosiasi dengan batulempung $\left(0.2 \times 10^{-3} \mathrm{SI}\right)$, dolomit $\left(0.0815 \times 10^{-3}\right)$, dan breksi $\left(0.7802 \times 10^{-3} \mathrm{SI}\right)$.
\end{abstract}

Kata kunci: Metode geomagnet, Mineral Sulfida, Forward Modelling, Disseminated

\begin{abstract}
The method used in this study is geomagnetic method in which is conducted at Libureng, district of Bone, South Sulawesi. The measurement points in this study are 65 points and $120 \mathrm{~m}^{2}$ wide to identify the distribution of sulphide minerals. A length on each line is 100 meters with interval 20 meters using a magnetometer tool. Data are corrected using upward continuation and modelled with forward modelling method using Mag2dc software. Value of anomaly from data analysis ranges from -1700 to $8000 \mathrm{nT}$. Interpretation shows that andesite igneous rocks $\left(1.6801 \times 10^{-3}\right)$ intruded the limestone $\left(0.3554 \times 10^{-3}\right)$. Distribution of sulphide minerals is disseminated and associated with claystone $(0.2 \mathrm{x}$ $\left.10^{-3}\right)$, dolomite $\left(0.0815 \times 10^{-3}\right)$, and breccia $\left(0.9079 \times 10^{-3}\right)$.
\end{abstract}

Key words: Geomagnetic Methods, Sulphide Minerals, Forward Modelling, Disseminated.

\section{Pendahuluan}

Mineral sulfida berupa ikatan antara sulfur dan logam dijumpai tersebar di alam dalam kadar dan dimensi kecil sampai besar. Pemanfaatan cebakan mineral sulfida dengan mengekstrak bijih menjadi komponen bernilai ekonomi yang dapat terdiri dari logam, bahan kimia dan bahan baku untuk industri lain. (Suprapto, 2012)
Pirit terbentuk di sekitar wilayah gunung api yang memiliki kandungan sulfur yang tinggi. Proses mineralisasi terjadi pada tempat - tempat keluarnya atau sumber sulfur. (Danisworo, 2010).

Berdasarkan hasil penelitian sebelumnya yang telah dilakukan (Latuconsina, 2015) ditemukan beberapa daerah yang memiliki prospek mineral Sulfida di Libureng, 
Bone. Keberadaan mineral tersebut ditunjukkan oleh kenampakan zona alterasi dan singkapan sekunder di daerah sungai Walanae dijumpai bentuk endapan mineral secara disseminated.

Berbagai macam metode geofisika yang dapat digunakan untuk menggambarkan model bawah permukaan, salah satunya adalah metode geomagnet.

\section{Landasan Teori}

Gaya magnet yang ditimbulkan oleh dua kutub yang terpisah dengan jarak $r$ dan muatannya masing-masing $m_{1}$ dan $m_{2}$ diberikan oleh:

$$
\vec{F}=\frac{1}{\mu} \frac{m_{1} m_{2}}{r^{2}} \hat{\mathrm{r}}
$$

Kuat medan magnet didefinisikan sebagai gaya per kutub, yaitu:

$$
\vec{H}=\frac{\vec{F}}{m_{2}}=\frac{1}{\mu} \frac{m_{1}}{r^{2}} \hat{\mathrm{r}}
$$

Bila benda magnetik diletakkan dalam medan magnet luar $\left(\mathrm{H}^{\prime}\right) \overrightarrow{ }$, kutub-kutub internalnya akan menyearahkan diri dengan $\mathrm{M}^{\rightarrow}$ dan terbentuk suatu medan magnet baru, yaitu:

$$
\overrightarrow{H^{\prime}}=4 \pi \vec{M}
$$

Medan magnet totalnya disebut dengan induksi magnet $\vec{B}$ (Induksi Magnet) dan dituliskan sebagai:

$$
\vec{B}=\vec{H}+\overrightarrow{H^{\prime}}
$$

Dalam kemagnetan dikenal suatu sifat dasar yaitu kerentanan magnet (suseptibilitas magnet, $k$ ) dalam ruang hampa $k=0$. Magnitudo suatu medan magnet bergantung pada kerentanan medan magnet tersebut. Intensitas magnetisasinya dapat ditulis sebagai berikut (Telford and Sheriff, 1990):

$$
\vec{M}=k \vec{H}
$$

jadi, kerentanan magnet adalah suatu ukuran besar kecilnya suatu intensitas magnet. Suatu benda yang mudah terimbas oleh medan magnet luar memiliki suseptibilitas magnet tinggi (Abdullah, dkk 2014) Dengan $1+4 \pi k$ sama dengan permeabilitas magnetik $(\mu)$ yang juga merupakan perbandingan antara $\vec{B}$ dan $\vec{H}$. Atau ditulis sebagai persamaan:

$$
\vec{B}=\mu \vec{H}
$$

\section{Metode Penelitian}

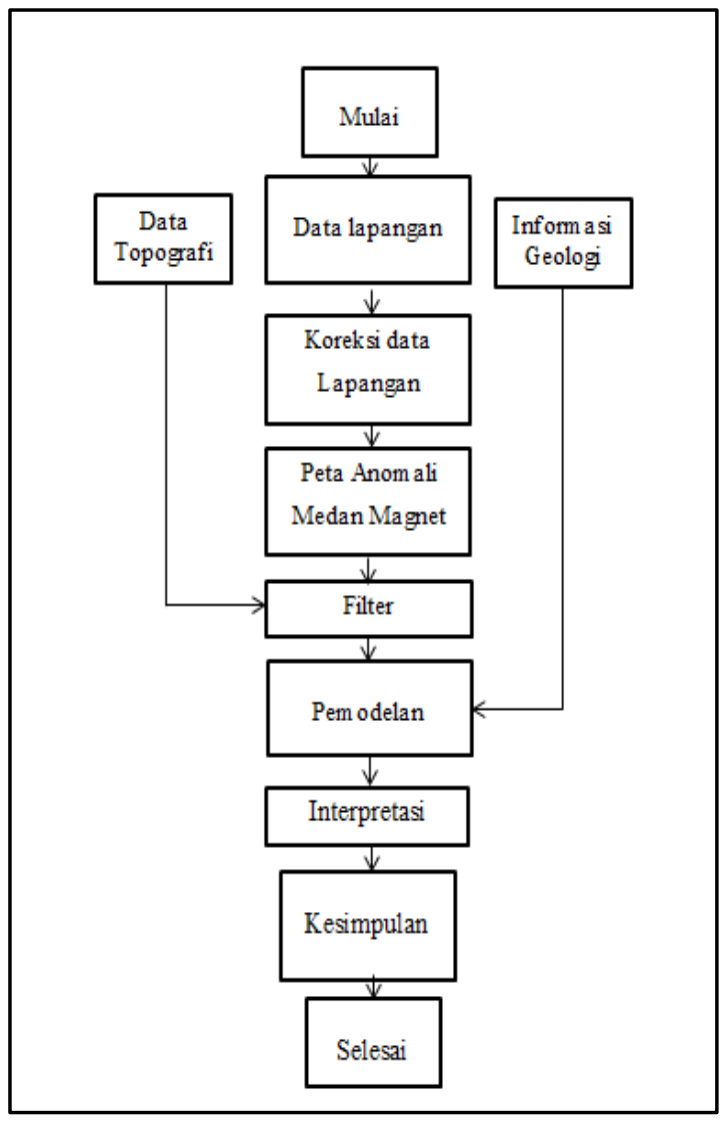

\section{Hasil Dan Pembahasan}

Pengukuran dilakukan dari titik base dan dilanjutkan ke titik pengukuran dengan jumlah titik pengukuran sebanyak 65 titik pengukuran di lapangan terdiri dari 6 Lintasan yang panjang masing-masing lintasan $100 \mathrm{~m}$ dengan spasi $20 \mathrm{~m}$. Koreksi diurnal change rate dilakukan untuk menghitung nilai laju perubahan di base.

Koreksi harian digunakan untuk mengurangi pengaruh harian dari efek gaya magnet oleh matahari. Koreksi IGRF digunakan utuk menghilangkan efek gaya 
magnet dari internal bumi, berdasarkan IGRF yang di sediakan oleh NOAA (National Oceanic Atmospheric Administration) Geophysical data center diperoleh nilai intensitas magnetik sebesar 42.848,20 nT dengan sudut inklinasi $25.7801^{\circ}$ dan deklinasi $0,9562^{\circ}$.

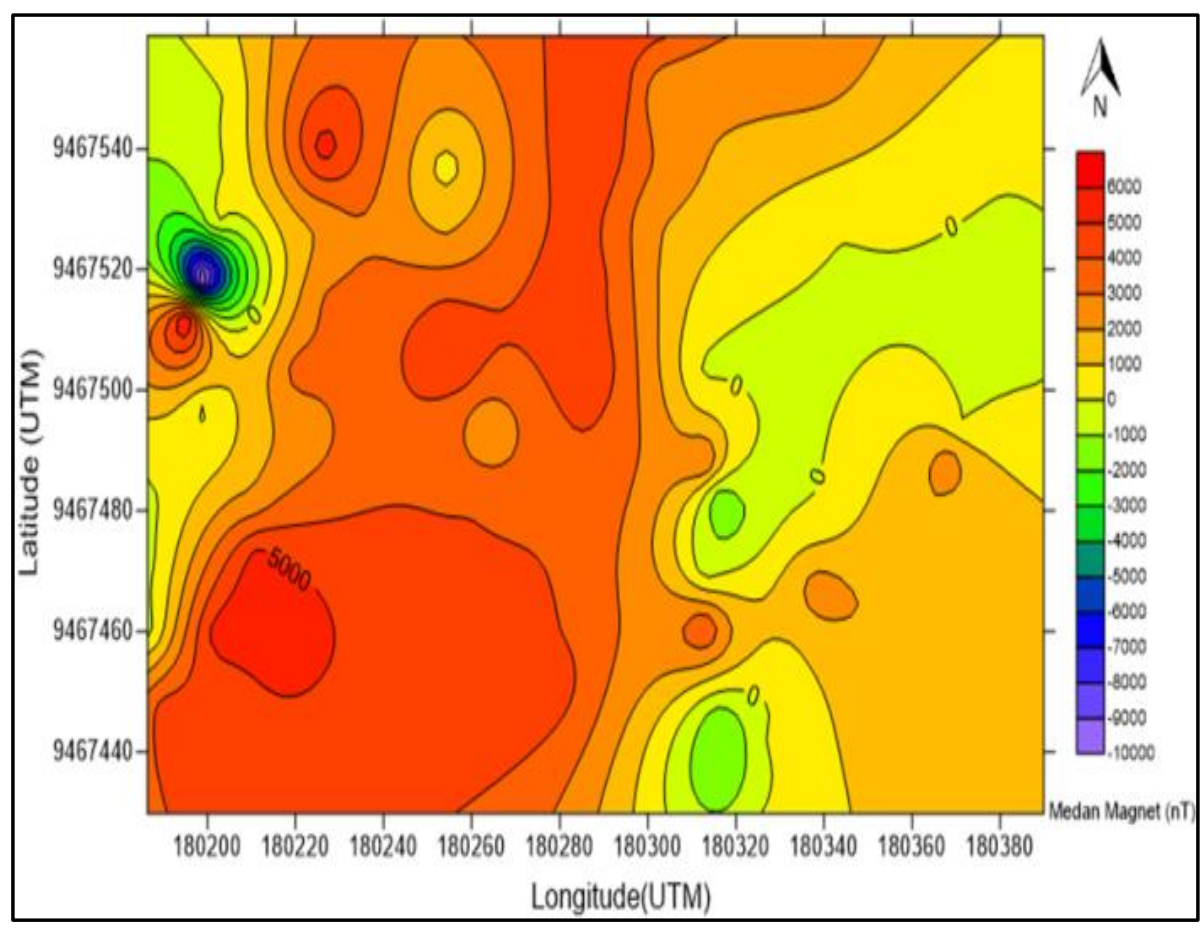

Gambar 1. Peta kontur anomali total medan magnet daerah penelitian.

Kontinuasi yang dilakukan adalah Upward Continuation, dimana kontinuasi upward ini berfungsi menaikan bidang pengamat ke atas dari body anomali untuk mendominankan body anomali yang terbaca pada peta anomali magnetik total, selain dilakukan filter Upward Continuation, dilakukan pula reduksi ke kutub. Proses reduksi ke kutub untuk mendapatkan peta kontur anomali magnetik yang melemahkan pengaruh sudut inklinasi magnetik.

Data yang dibutuhkan dalam membuat model adalah data anomali magnetik residual. Hal tersebut dilakukan karena anomali magnetik residual merupakan magnetik material yang berada pada permukaan bumi. Data penampang yang dipilih untuk diinterpretasikan sebanyak 2 irisan penampang seperti yang terlihat pada Gambar 2.

$\begin{array}{lcc}\text { Interpretasi } & \text { kuantitatif } & \text { dilakukan } \\ \text { Pemodelan } & \text { pada Mag2dc } & \text { dilakukan }\end{array}$ dengan mencocokkan antara kurva anomali model dengan kurva anomali observasi Berikut parameter model yang digunakan adalah:

\begin{tabular}{|l|l|}
\hline Profil bearing & $: 0^{\circ}$ \\
\hline Referensi ketinggian & $: 1,0 \mathrm{~m}$ \\
\hline Kedalaman maksimum & $: 100 \mathrm{~m}$ \\
\hline $\begin{array}{l}\text { Geometric field } \\
\text { parameters, }\end{array}$ & $: 42.834,9 \mathrm{nT}$ \\
\hline $\begin{array}{l}\text { Intensitas medan } \\
\text { magnet bumi }\end{array}$ & $:-25,7801$ \\
\hline $\begin{array}{l}\text { Inklinasi medan } \\
\text { magnet bumi }\end{array}$ & $: 0.9562$ \\
\hline $\begin{array}{l}\text { Deklinasi medan } \\
\text { magnet bumi }\end{array}$ & $: 0,01$ \\
\hline Kontras suseptibilitas & $: 100 \mathrm{~m}$ \\
\hline Panjang strike
\end{tabular}

Pemodelan dilakukan dengan mencocokkan antara kurva anomali model terhadap kurva anomali observasi. Setelah diperoleh kecocokan antara dua kurva ini, maka diperoleh lima benda anomali yang dapat diasumsikan sebagai batuan bawah 
permukaan lintasan B - B' di daerah

Slice B - B'

penelitian, seperti terlihat pada Gambar 2.

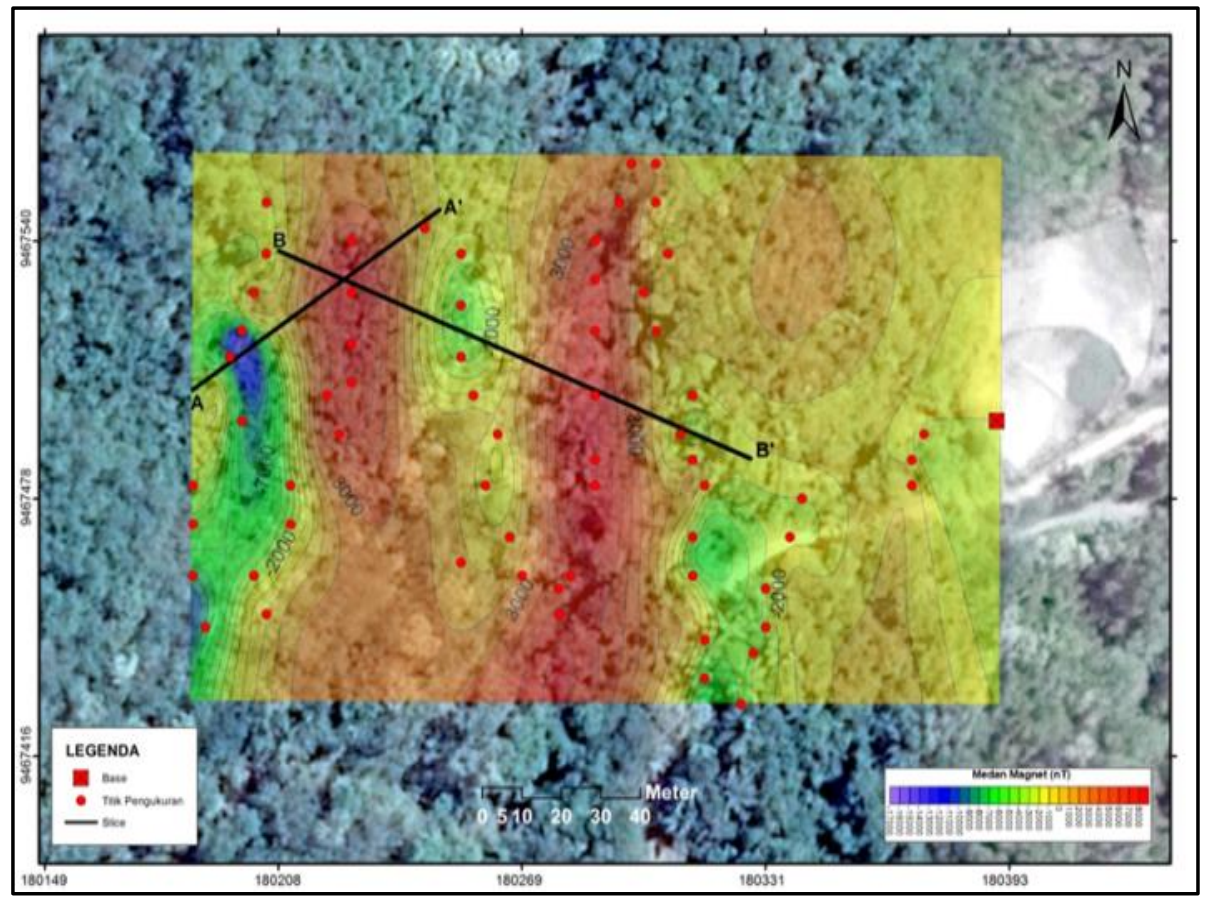

Gambar 2 Peta anomali residual yang telah dislice

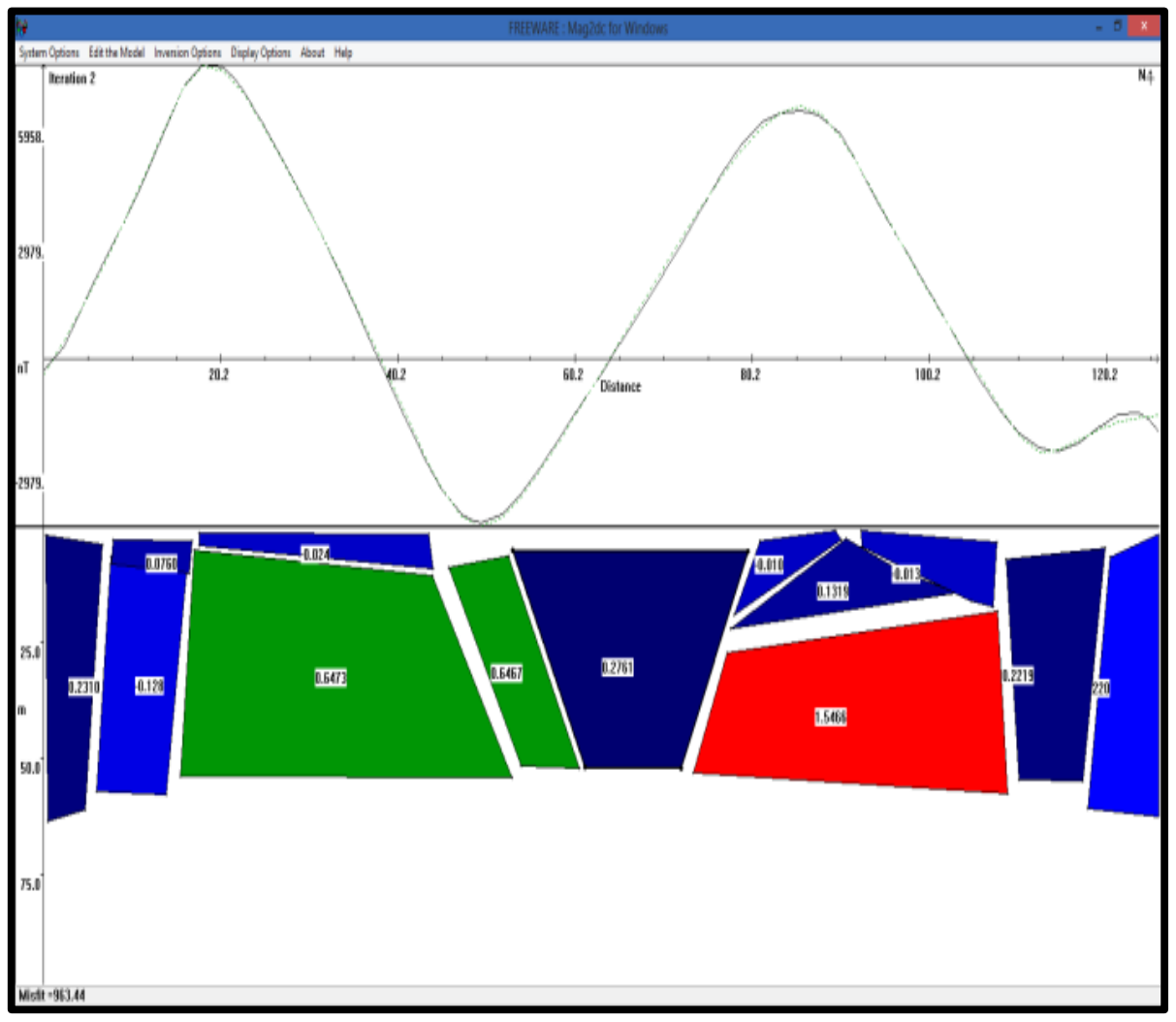

Gambar 3 Profil anomali model slice A -A'

Model penampang slice B - B' terdapat 5 model blok batuan (pada gambar 3) yang mana dapat diinterpretasikan sebaran endapan pirit berada pada 3 model blok 
batuan yang pertama pada jarak $7 \mathrm{~m}-18$ $\mathrm{m}, 58 \mathrm{~m}-80 \mathrm{~m}$ dan $117 \mathrm{~m}-125 \mathrm{~m}$. Berada pada kedalaman $4-8 \mathrm{~m}$ yang berasosiasi dengan batulempung dengan nilai suseptibiltas $0.2 \times 10^{-3}$ SI yang mana ketiganya berada di sekitar area sungai. Kedua pada jarak $18 \mathrm{~m}$ - $58 \mathrm{~m}$ pada kedalaman $52 \mathrm{~m}$ dimana sama seperti Slicel breksi (piroklastik) bersisipan dengan batugamping (Model 1) nilai suseptibiltasnya $0.7802 \times 10^{-3} \mathrm{SI}$. Ketiga pada jarak $80 \mathrm{~m}$ - $117 \mathrm{~m}$ pada kedalaman $2 \mathrm{~m}-25 \mathrm{~m}$ yang merupakan batugamping pasir nilai suseptibiltasnya $0.1235-0.2654$ x $10^{-3}$ SI yang mana pada tebing sungai di sekitar area penelitian didapatkan pecahan batugamping pasir. Pirit yang terdapat pada model 1, 3, dan 4 berasal dari intrusi batuan beku andesit (model 5) yang kaya akan mineral pirit menerobos formasi Salo Kaluppang (Teol) yang dominan batugamping. Penampang resistivitas Lintasan 3 pada penelitian sebelumnya yang berpotongan dengan lintasan Slice 2 menyatakan terdapat andesit seperti pada gambar (model 5). Dari hasil uji sampel sulfur sulfida yang mengandung pirit dengan menggunakan pengujian XRF analyzer unsur-unsur yang terkandung yaitu : $\mathrm{SO}_{3} 72.13 \%, \mathrm{Fe}_{2} \mathrm{O}_{3} 27.16 \%, \mathrm{P}_{2} \mathrm{O}_{5}$ $0.51 \%, \mathrm{MnO} 0.043 \%, \mathrm{ZnO} 0.0014 \%$ yang mana unsur pembentuk utama pirit yaitu $\mathrm{Fe}$.

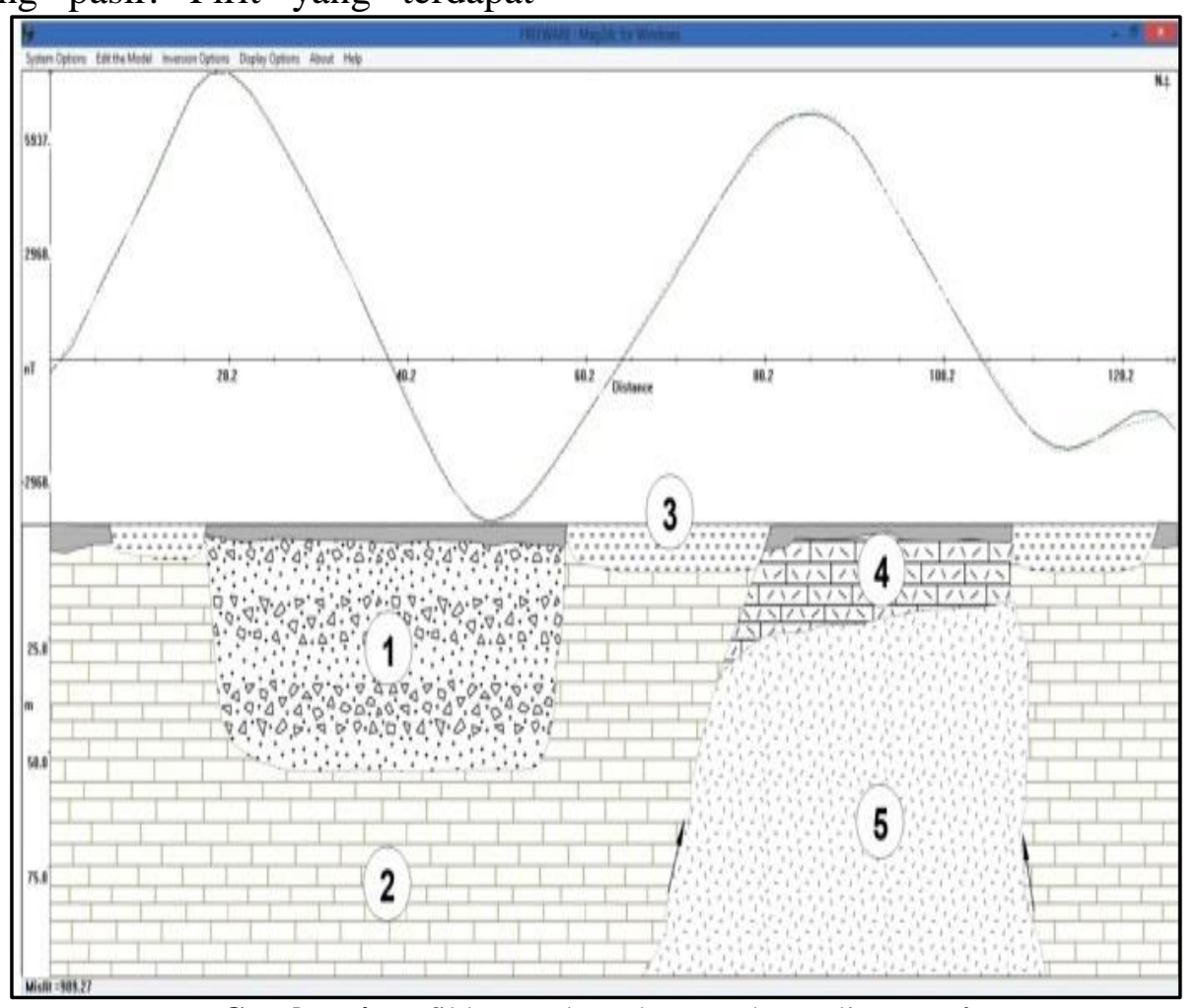

Gambar 4 Profil batuan bawah permukaan slice B -B'

\section{Kesimpulan}

1. Nilai suseptibilitas batuan di lokasi penelitian $0.2 \times 10^{-3}$ SI untuk batulempung, $0.9079 \times 10^{-3}$ SI untuk breksi, $1.6801 \times 10^{-3}$ SI untuk andesit, 0.3554-0.4096 x $10^{-3}$ SI untuk batugamping, $0.0815 \times 10^{-3} \mathrm{SI}$ dolomit dan 0.4803 x $10^{-3}$ SI untuk batugamping pasir.
2. Profil bawah permukaan daerah penelitian terdiri dari struktur geologi batuan sedimen gamping formasi Salo Kaluppang (Teos) yang di intrusi oleh batuan beku andesit pada penampang anomali magnetik di temukan batuan yang dominan adalah batuan sedimen gamping dengan nilai suseptibilitas $0.3554-0.4096 \times 10^{-3}$ SI dan terintrusi oleh oleh batuan beku andesit $1.6801 \mathrm{x}$ 
$10^{-3} \quad$ SI sehingga mengakibat berasosiasinya mineral pirit dalam tubuh andesit ke batuan sedimen yang terdapat di daerah penelitian.

3. Mineral pirit tersebar secara disasminated di daerah penelitian berasosiasi dengan batulempung, dolomit dan breksi.

\section{Daftar Pustaka}

Abdullah, F.M., Sunaryo, dan Susilo, A., 2014."Pendugaan Jenis Batuan Bawah permukaan Daerah Bendungan Karangkates Menggunakan Metode Geomagnetik". Jurusan Fisika FMIPA Universitas Brawijaya.Malang.

Danisworo, A. 2010." Mineralogi dan Batuan." Gramed. Yogyakarta.

Latuconsina, H. (2015). "Identifikasi Sebaran Mineral sulfida (pirit) Menggunakan Metode Induksi Polarisasi di Daerah Libureng." Prodi Geofisika, FMIPA UNHAS. Makassar.
Singarimbun, A., Bujung, C.A.N., dan Fatihin, R.C., 2011."Penentuan Struktur Bawah Permukaan Area Panas Bumi Patuha dengan Menggunakan Metode Magnetik".Jurnal Matematika dan Sains. Bandung.

Sukamto, R. 1982. "Geologi Regional Lembar Pangkajene dan Watampone bagian Barat." PPPG. Bandung.

Suprapto, S. J. 2012. "Pemanfaatan dan Permasalahan Endapan Mineral Sulfida Pada Kegiatan Pertambangan. 'Kelompok Kerja Konservasi - Pusat Sumber Daya Geologi.

Telford and Sheriff. 1990. Applied Geophysics. Cambridge University.

Yudianto, Harri dan Setyawan, Agus. 2014. "Interpretasi Struktur Bawah Permukaan Daerah Manifestasi Panasbumi Gedong Songo Gunung Ungaran Menggunakan Metode Magnetik. "Jurusan Fisika, Universesitas Diponegoro. Semarang. 